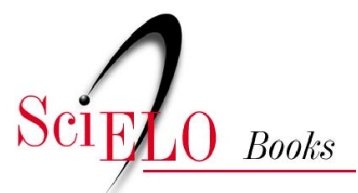

\title{
Conclusions and analysis
}

\author{
Bernardo Sorj
}

SORJ, B. Conclusions and analysis. In SORJ, B., CANTLEY, M., and SIMPSON, K., eds. Biotechnology in Europe and Latin America: prospects for co-operation [online]. Rio de Janeiro: Centro Edelstein de Pesquisas Sociais, 2010. pp. 210-219. ISBN: 978-85-7582-036-6. Available from SciELO Books $<$ http://books.scielo.org $>$.

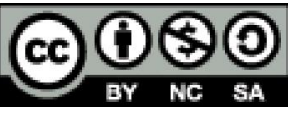

All the contents of this chapter, except where otherwise noted, is licensed under a Creative Commons Attribution-Non Commercial-ShareAlike 3.0 Unported.

Todo o conteúdo deste capítulo, exceto quando houver ressalva, é publicado sob a licença Creative Commons Atribuição Uso Não Comercial - Partilha nos Mesmos Termos 3.0 Não adaptada.

Todo el contenido de este capítulo, excepto donde se indique lo contrario, está bajo licencia de la licencia Creative Commons Reconocimento-NoComercial-CompartirIgual 3.0 Unported. 


\section{CONCLUSIONS AND ANALYSIS}

Bernardo Sorj

The three days of discussion confirmed the importance of biotechnology for Latin America not only in such fields as tropical medicine and nutrition which are vital to basic welfare, but also in areas directly contributing to economic growth and development.

Biotechnology has a role to play in strengthening Latin America's growth prospects and trade performance by:

- improving crop yields;

- favouring import substitution in agriculture and industry;

- extending the pharmaceutical industry into new areas;

- and, perhaps above all, capturing the creativeness and entrepreneurship of Latin America's smaller technology-based firms.

If these hopes are realised biotechnology will feed into structural adjustment efforts and so contribute to relaunching growth, and overcoming the debt problem.

But these hopes will not be realised overnight:

- there is a shortage of scientists able to place the necessary expertise at the service of Latin American industry;

- research institutes and universities cannot keep pace with the demand;

- information concerning available technologies which could be adapted to the needs of Latin American industry and agriculture is lacking;

- smaller firms possessing such technologies in Europe and elsewhere may, because of their size, lack the means to establish contacts with counter-part firms in Latin America.

This situation poses a challenge to research institutes, industry, governments, regional organisations in Latin America and to the European
Community. SOBELA was an impressive demonstration of the will of all parties concerned to meet this challenge.

Where do we go from here, now that a certain number of contacts have been made? What can Europe and Latin America do, working together as partners, to further co-operation in the field of biotechnology? How in particular can the Community, by virtue of its own experience in promoting cross-national research on biotechnology and more generally of economic co-operation help assure a follow-up which is worthy of the many valuable interventions made at the seminar?

There are at least three fields which call for immediate action:

A. Information. The improvement of the two-way flow of information between Europe and Latin America on new developments in biotechnology: the Commission is ready to explore possibilities for improving data bases, facilitating exchanges between research institutes, organising specialised seminars and conferences to ensure that researchers in our two continents are informed of each others efforts, within the normal constraints imposed by commercial considerations;

B. Training. Latin America is producing an increasing number of scientists but their number falls short of that required by the rapid growth of biotechnology.

The Community and its Member States can help overcome this problem by:

- making available experts to work with Latin American research institutes and biotechnology-based enterprises;

- arranging traineeships for Latin American scientists with Community firms and research institutes;

- providing assistance for Latin American biologists to pursue advanced studies in Europe;

- improving information on training possibilities throughout the Community.

C. Industrial Co-operation. These three days' discussion have shown that both sides have an interest in joint ventures and other forms of 
collaboration between firms and research institutes on either side of the Atlantic. Such arrangements are among the most effective instruments for technology transfer.

The Commission has recently proposed to the Council that henceforth the Community should do more to promote industrial co-operation with enterprises in our partner countries in Latin America and elsewhere in the developing world.

We will examine together in the coming months how best these ideas can be applied to the field of biotechnology.

You can rest assured that the European Commission will do whatever is within its power to support those efforts which you, who are dose to the reality of industry and research, decide jointly to undertake.

Together we will examine the kind of instruments by which we could develop and implement joint initiatives in the fields covered by this seminar.

For us this seminar has served as a valuable learning experience, an example of the kind of initiative which can help bring researchers and industrialists in Europe and Latin America closer together.

The many suggestions put forward will help us to develop new forms of co-operation not only in biotechnology but also in other advanced fields where Europe and Latin America can learn from each others' experience.

\section{SOBELA Analysis}

Advanced technologies pose new challenges for developing countries and their relationships with the developed world. How can high technology be integrated into a development strategy? What is the best basis for cooperation between Europe and Latin America in the context of a global market challenged by Japan and the USA?

It is the belief of the Editors that the SOBELA seminar and this volume provide some valuable indications of how the preceding questions might be addressed.

SOBELA was organised in two parts: the meeting itself and a number of satellite visits to European countries by members of the Latin American delegations. Proposals for possible co- operation were evaluated by a questionnaire distributed to Latin American delegates both before and after SOBELA. The following table shows the level of response.

\begin{tabular}{|lccc|}
\hline Table 1. Questionnaire replies. & & & \\
\hline Country & Delegates & Replies & Percentage \\
\hline Andean Pact & $9(11)^{*}$ & 4 & 45 \\
Argentina & 10 & 6 & 60 \\
Brazil & $17(26)^{*}$ & 11 & 65 \\
Mexico & 5 & 3 & 60 \\
Totals & $41(52)^{*}$ & 24 & 59 \\
\hline * The number in parentheses includes journalists and governmental representatives, not \\
directly involved in biotechnology.
\end{tabular}

The number of co-operation proposals advanced by each delegation attests to a broadly similar level of interest. If numbers are extrapolated to include all delegates from Latin America some 200 proposals for cooperation may have been initiated.

\begin{tabular}{|l|c|c|c|}
\hline \multicolumn{3}{|l|}{ Table 2. Co-operation proposals by delegation. } \\
Country & Total & Extrapolated total* & Average proposals per delegate \\
Andean Pact & 28 & 58 & 6.4 \\
Argentina & 23 & 38 & 3.8 \\
Brazil & 36 & 56 & 3.3 \\
Mexico & 10 & 17 & 3.4 \\
Totals & 97 & 169 & 4.1 \\
*extrapolation to 100\% rate of reply for each delegation. \\
\hline
\end{tabular}

The following table summarizes proposals on a country by country basis.

\begin{tabular}{|lccccccccccccc|}
\hline \multicolumn{10}{|l|}{ Table 3. Co-operation proposals, synopsis. } \\
\hline \multicolumn{1}{|c}{ Countries } & $B$ & $F$ & $G R$ & NL & IRL & $I$ & $P$ & $E$ & $G B$ & $D$ & $L A$ & Total \\
\hline Andean Pact & 6 & 4 & - & 2 & 1 & 4 & - & 2 & 1 & 5 & 2 & 27 \\
Argentina & 6 & 7 & - & 1 & - & - & - & 1 & 7 & 2 & - & 24 \\
Brazil & 12 & 11 & 1 & 7 & - & - & 2 & 1 & 1 & 2 & - & 36 \\
Mexico & 2 & - & 1 & 2 & - & - & - & 2 & 1 & 1 & 1 & 10 \\
Totals & 26 & 22 & 2 & 12 & 1 & 4 & 2 & 6 & 10 & 10 & 3 & 98 \\
\hline
\end{tabular}

The above figures reflect the special efforts made by Belgium, France and the Netherlands who organised visits within their countries for members of the Latin American delegations. Although the United Kingdom did not host any visits it is notable that a strong tradition of co-operation served as the basis for a number of proposals. 


\begin{tabular}{|lccccc|}
\hline Table 4. A sectorial analysis of replies. & & & \\
\hline \multicolumn{1}{|c}{ Countries } & Health & Agro & Energy & Others* & Total \\
\hline Andean Pact & 8 & 6 & - & 13 & 27 \\
Argentina & 10 & 4 & - & 10 & 24 \\
Brazil & 4 & 24 & 1 & 7 & 37 \\
Mexico & 1 & 4 & - & 5 & 10 \\
Totals & 23 & 38 & 1 & 35 & 38 \\
\hline * Refers essentially to training programmes in relevant fields. \\
\hline
\end{tabular}

There is a clear division of interest among the Latin American states, with Argentina and the Andean Pact focusing on Health Care and Brazil and Mexico focusing on Agriculture. Almost half of the proposals related to agriculture and a quarter to health care.

The type of European institution interested in co-operation with Latin America is indicated in the following table.

\begin{tabular}{|lccc|}
\hline \multicolumn{4}{|c|}{ Table 5. European Institutions interested in proposals. } \\
\hline \multicolumn{1}{|c|}{ Countries } & Private & Public & Total \\
\hline Andean Pact & 3 & 24 & 27 \\
Argentina & 11 & 13 & 24 \\
Brazil & 21 & 16 & 37 \\
Mexico & 4 & 6 & 10 \\
Totals & 39 & 59 & 98 \\
\hline
\end{tabular}

Overall there was a balance between private and public sector proposals for co-operation. The Brazilian delegation, which included a significant number of entrepreneurs showed the greatest tendency to private industrial co-operation.

It is still unclear how many of these early overtures of interest will ultimately become manifest as contractual agreements. This will depend in some measure on the active involvement of states and individuals in initiatives discussed in the concluding remarks.

A most important consequence of SOBELA was the stimulation of an identity amongst those Latin American institutions involved in biotechnology. Strong institutions, both public and private, are of fundamental importance in promoting and sustaining European/ Latin American co-operation. It is important to note that the timing of SOBELA in April 1987 was critical, coming just as Latin American countries were taking the first steps in the establishment of private and governmental enterprises in the field of biotechnology. Brazil had just launched the
Association of Biotechnology Enterprises (ABRABI). The National Secretariat of Biotechnology of the Ministry of Science and Technology, in its second year, was defining its programme of activity. Argentina, with a lesser degree of institutionalisation, had a government body responsible for promoting biotechnology, and a forum for encouraging the interaction of entrepreneurs. Mexico has long had government sponsored activities in biotechnology, but no private industrial sector of note. The Andean Pact countries are only now formulating their biotechnology programme.

The first important, and unforeseen, role of SOBELA was to crystallise the institutionalisation of Latin American biotechnology. The seminar functioned both as a Latin America/Europe meeting and as a rare Latin American forum, where representatives from the differing Latin American states were together able to discuss strategy. Thus SOBELA stimulated not only inter-continental co-operation, but also intra-continental co-operation. The massive Brazilian delegation probably had a stimulating effect on the other Latin American delegates, especially in the sense of emulating the Brazilian association of enterprises with its large private sector representation.

SOBELA fulfilled a second role in indicating a 'modus operandi' for European/Latin American co-operation that may surmount many of the problems encountered in such international co-operative ventures. The inclusion of representatives from government, industry and research institutions allowed the different influences to counterbalance and complement each other. Too often there is a tendency for policy makers to be rhetorical, entrepreneurs narrow minded and academics unrealistic. In Latin America, political instability and sometimes ideological pressures, can increase those tendencies. It is fundamental that all sectors work together to ensure the continuity and efficacity of international co-operation.

As an exercise in awareness SOBELA filled a third role, allowing Latin American and European delegates to evaluate the advantages of cooperation. Latin American delegates were most enthusiastic as exemplified by the following comments:

- 'We felt that Europe is capable of confronting America and Japan at the scientific and technological level'

- 'SOBEla was the first but important step in a difficult, time consuming, process' 
- 'European-Latin American relations should be based on a fair exchange by which the first receive technology, and the second an important consumer market'

- 'The formation of human resources is a central interest for Latin America and a precondition for the effective absorption of European technology'

- 'We need to create direct links between European and Latin American entrepreneurs'

- 'We need greater selectivity in the field of industrial co-operation, taking into consideration existing infrastructure, markets, technical capacity and patent laws'

- 'We need to study the mechanisms by which Europe increases the links between enterprises and universities'

- 'We need to consolidate realistically our national programmes of biotechnology in order to make clearer what we need and have to offer'

- 'We need to discuss negotiation models capable of satisfying the expectations of both sides'

- 'We discovered that Europe has technologies that will find their ideal application in Latin America'

- 'European documents related to legal problems, regulation and promotion of biotechnology should be diffused and a workshop organised on specific topics of common interest'

- 'I was impressed by the diversity of interest and idiosyncrasies of the various European countries, and at the same time by their conviviality within a common framework

- 'SOBELA was important for us (Andean Pact) because we are in a stage of definition of our national programme and priorities'

- 'The interpersonal relations established during SOBELA will be central to our future co-operation with Europe. SOBELA expressed the will of the Commission to increase links with Latin America.
These efforts should have continuity through open communication channels, and the realisation of new meetings'

\section{The Challenges}

The quality and quantity of contacts that were established between Latin American and European biotechnology entrepreneurs, and the facility with which they were set up indicate that the biotechnology sector is particularly well placed for the development of economic co-operation between the two continents, especially between small and medium scale enterprises (SMEs). The reasons for this lie in the special nature of biotechnology based SMEs. Relatively small amounts of capital are needed to launch a joint venture operation, and importantly company directors often have an academic back-ground with international languages and experience.

In a sector where industrial and academic skills are highly integrated it is possible to exploit the well established international programmes in scientific training and research to the benefit of science based commercial development. SOBELA raised the prospect of using biotechnology as a tool for promoting international co-operation. Many problems still exist and will need to be resolved if effective inter-continental partnerships are to be effected. It will be critical that in such relationships a fair exchange is effected: for European firms, a reasonable return on investment and presence in a developing world market, and for Latin American countries and organisations, the production of essential goods within the framework of a favourable technology transfer and co-operation environment.

In order to advance the interests of both sides further exchange and experience is required. The controversial topic of patent legislation must be confronted. This topic is a subject of debate in Latin America, and indeed the world press. The USA has recently adopted a most hostile stance towards Latin American latitude on the patents issue. Internal debate is moving towards a consolidation of opinion and in some states, Mexico for example, legislation is being enacted to give full patent protection to pharmaceuticals and food products. Europe should seek active participation in these discussions, at European Commission, national governmental and industrial levels, thus shaping Latin American positions for the future. This will not be achieved by confrontation and polarisation, but by exchanges of opinion and political concertation. 
Europe's presence in Latin America is mediated predominantly by large companies. There is however much scope for the active participation of European SMEs, which are usually more open to the technology transfer schemes expected by Latin American countries.

Increasing co-operation between European and Latin American SMES is a difficult objective to realise, not least because of limited information, provincial attitudes, and simple ignorance of the scope of possibilities for international co-operation. On the basis of arguments presented in drafts of this volume the European Commission will explore ways to make available the information, interface operational units and concertation activities needed to transform the spirit of SOBELA into a permanent and expanding reality.

SOBELA was not simply a seminar on biotechnology in Europe and Latin America held in April 1987. It is an ongoing activity, in which Europe is demonstrating its capacity to be the active partner and focal point for the constant effort needed to turn around the economies of developing countries through the medium of high technology. 